\title{
Life Cycle Inventory of HDPE Bottle-Based Liquid Milk Packaging Systems
}

By Jay Singh, ${ }^{1}$ Aric Krasowski ${ }^{1}$ and S. Paul Singh ${ }^{2}$

${ }^{1}$ Industrial Technology, Cal Poly State University, San Luis Obispo, CA

${ }^{2}$ School of Packaging, Michigan State University, East Lansing, MI

This study aims at providing a relatively straightforward methodology to serve as a decision-making tool when more than one packaging solution could be available to a user. It involves a life cycle inventory (LCI) analysis and comparison of three currently available 3.79 l (1 gallon) packaging systems for liquid milk. Two of the primary container types studied use reusable plastic crates (RPCs) for stacking and shipping, while the third type is a heavier duty container that does not require secondary shipping containers. The three primary containers studied are identified as original, cube and stackable throughout this paper. The study shows that the use of RPCs for controlled environment distribution reduces the material requirements of the primary containers and therefore reduces the overall $\mathrm{CO} 2$ emissions. It was also found that though the transportation-related emissions varied between the packaging systems for the two end-of-life scenarios considered, it had the lowest overall effect on the $\mathrm{CO} 2$ emissions and use of energy. The study concludes that transportation weight limits must be considered as a limiting factor in package design for liquid products, as trailers 'weigh out' before they 'cube out.' As related to the LCI impacts, this study found that the original and cube container-based packaging systems have better overall per functional unit performance in comparison with the stackable design. It was also noted that scorecards based on the Wal-Mart format do not accurately define the environmental impacts posed by packaging systems.

\section{INTRODUCTION}

Life cycle assessment (LCA) is the investigation and valuation of the environmental impacts of a product or service with the goal of comparing the full range of environmental damage assignable. ${ }^{1}$ LCA attempts to predict the overall environmental burdens associated with the provision of the product and identify particularly burdensome or wasteful processes therein. ${ }^{1}$ Life-cycle inventory (LCI) quantifies material use, energy use, environmental discharges and wastes associated with each stage of a product system over 
its life cycle, from raw material extraction to material processing, product fabrication, use, reuse or recycling, and ultimate disposal. ${ }^{1}$ The LCA/LCI approach has become widely accepted in both Europe and the USA. ${ }^{2-7}$

This study aims at evaluating and comparing the environmental impacts associated with the packaging systems for three types of 3.79 l (1 gallon) high-density polyethylene (HDPE) plastic milk containers available in the US retail market. It was coordinated with a major California-based milk producer and distributor that assisted in collecting partial data related to the LCI analysis. A newly developed packaging-focused LCI software was adopted in conducting this study.

According to the USDA's Agricultural Statistics Board, 8.32 million milk cows in the 23 major US states produced $85.87 \times 10^{9} \mathrm{~kg}$ of liquid milk in $2009 .{ }^{8}$ With $19.28 \%$ of the milk cows and approximately $21 \%$ of the entire nation's liquid milk production, California is the largest producer of liquid milk in the USA. ${ }^{8}$ According to the preliminary report by the Innovation Centre for Dairy Science's sustainability initiative, an estimated $28 \times 10^{6}$ metric tons of CO2 equivalent emissions can be sourced to liquid milk, from crop production to retail sale. ${ }^{9}$ This includes 395 liquid milk plants in the USA that pasteurize and package $21.9 \times 10^{9} \mathrm{l}$ of milk, which accounts for about $5.1 \times 10^{9}$ metric tons of greenhouse gas (GHG) emissions each year. The centre has set a goal to reduce $25 \%$ of the CO2 equivalent emissions from the entire process by 2020.

There have been several studies that used LCA to evaluate packaging used for dairy products. One such study evaluated seven systems - single-use and refillable glass bottles and HDPE containers, paperboard gable-top cartons, linear low-density polyethylene (LDPE) flexible pouches and polycarbonate refillable bottles - for life cycle, solid waste, energy and costs. ${ }^{10}$ The major attributes for the containers studied were low fabrication cost, barrier properties comparable to glass, low weight and shatter resistance afforded by plastics, resealability, low material production energy per unit delivered, low material production of solid waste per unit delivered and high end-of-life recyclability. For a functional unit (FU) of 3785 l of milk delivered for household consumption, the study concluded that the refillable HDPE and polycarbonate containers and the flexible pouch were the most environmentally preferred packaging systems with respect to life-cycle energy and solid waste. This study excluded delivery systems for on-site users, such as lunch programmes, of fresh dairy milk and did not address impacts associated with milk production and filling.

Another study that analysed the environmental impact of future supply chains for dairy products based on the LCA methodology concluded that the environmental effects of the milk supply chain must consider the entire chain. ${ }^{11}$ It also states that the amount of packaging materials used is an important factor as is the transportation of the dairy 
products to households. A recent study demonstrated how LCA may be used with a keycomponent perspective in the Swedish post-farm milk chain. ${ }^{12}$ The study considered milk, yogurt and cheese, and concluded that reduced wastage lowers most impacts for all three products. Using less energy is the most efficient improvement for retailers, and reducing wastage gives unequivocal positive results from the household perspective.

Another study performed an LCI based on increasing recycling rates of cardboard (paperboard), from $2 \%$ up to $22 \%$, for aseptic packaging systems for milk. ${ }^{13}$ It concluded that the increase in the recycling rate brings about a series of benefits in terms of reduction in energy and natural resource consumption, air pollutants and most water emissions. Increasing the recycling rate improves the overall environmental performance of the aseptic Tetra Pak ${ }^{\mathrm{TM}}$ system for milk.

It may be noted here that the protection function of any package needs to be emphasized in any packaging solution. The primary reason is that, if a package, no matter how sustainable, creates product loss, it creates not only an environmental burden due to the wasted packaging but also the waste associated with the product it carries. ${ }^{12}$ There are many associations between quality attributes of a package and its environmental impacts for food packaging. The results of a recent study show that there are apparent possibilities of increasing customer acceptance while decreasing the environmental impact of food packaging systems, especially when the optimum packaging has been designed to reduce product loss. ${ }^{14}$

The initial phase of LCA includes defining the goals and scope of a study and the collection and calculation of LCI data. LCI data help quantify the material, energy and emissions associated with a functional system, which in our study was 3.79 l (1 gallon) of packaged liquid milk (details in the next section). This phase precedes the LCI assessment phase (LCIA), which involves the classifi cation, characterization and evaluation of these data in relation to ecological impacts. The fourth and last phase is the interpretation where the data resulting from the LCI and LCIA phases are analysed in the context of the scope and study goals and the quality of any study conclusions assessed.

The main purpose of this study is to provide a relatively uncomplicated yet scientifi c methodology to serve as a decision-making tool when more than one packaging solution could be available to a user. For this reason, LCI rather than LCA was used in this study. This was established through the use of an LCI software designed especially for packaging. Energy, consumed for raw material production, package manufacturing, filling and distribution and credited for recycling, in MJ and GHGs in kg CO2 equivalent per FU are reported. Environmental burdens such as fresh water, smog and toxicity were not included in this study due to the limitations of the software used. 


\section{GOAL, SCOPE AND BOUNDARIES}

\section{Goal, scope and FU}

The goal of this study is to conduct an LCI analysis-based comparison of three types of 3.79 l ( 1 gallon) HDPE milk containers along with the distribution packaging required for each FU. The scope of the study ranges from the extraction of raw materials, their processing and formation for all packaging components, product filling and distribution and their end-of-life scenarios. The scope includes energy inputs and credits and GHGs in CO2 equivalents followed by the end-of-life disposal. The FU selected was 3.79 l (1 gallon) of packaged liquid milk delivered to institutional customers (on-site users) and retailers within $402 \mathrm{~km}$ from the processing and packing plant with a minimum of 2 weeks of shelf life at delivery.

The primary containers studied are shown in Figure 1 and are identified throughout this paper as original, cube and stackable. The original and cube designs require reusable plastic crates (RPCs) for distribution, whereas the stackable design does not. The closedloop (reusable) packaging components considered in this study are the polypropylene (PP) crates for the first two types of primary containers and the wooden pallets for all types of containers.

\section{Methods}

The framework of this study was adopted from the ISO 14040 guidelines. ${ }^{1}$ The SavvyPack ${ }^{\circledR} 2.0$ software system (Allied Development Corp., Burnsville, MN, USA), an LCI software program, and CAPE PACK v2.04 (Cape Systems Group, Inc., Piscataway, NJ, USA) pallet optimization software were used for this study. The SavvyPack ${ }^{\circledR}$ system measures energy usage and recovery and GHG emissions (CO2 equivalent), through each step of the supply chain, including resin and other raw material production, raw material transport, package manufacture, product filling and delivery to the retailers or institutional customers. The 'United States 3' data set option offered by the LCI software was selected for this study. This data set is based on production processes in the USA and includes biomass energy credits. The CAPE PACK design software consists of pallet pattern optimization tools. Its features include the ability to build pallet patterns, create new case sizes, design new product packages and consolidate case sizes.

The majority of raw material data required for the inventory analysis for the following were obtained from the SavvyPack ${ }^{\circledR}$ software: HDPE (bottles), LDPE (labels, caps 
and stretch wrap), polyethylene terephthalate (PET; band straps), PP (reusable crates), wood (pallets) and corrugated fibreboard (slip sheets). This software sources the data and keeps them updated to within 3 months from the Canadian Raw Materials Database, European Aluminum Association, European Commission, Finnish Environment Institute, International Iron and Steel Institute, National Renewable Energy Lab, Environmental Defense Fund Paper Calculator, Plastics Europe, and Sustainable Product Information Network for the Environment.

Information was also gathered from a major California-based milk producer and distributor and included plant layout, process equipment, support equipment, raw material transportation and product distribution networks. This information was assumed to be typical and was used through the study for the three types of package systems studied. The only variables changed were those directly related to the packaging design changes such as the secondary packaging requirements to optimize loads for transportation.

A scorecard methodology to provide a comparison between the three packaging systems studied was also incorporated in this study. This is particularly beneficial to all suppliers and retailers that are presently using scorecards to judge packaged products in terms of different metrics of sustainability. A scorecard may be construed as a document reflecting in summary form the strategic objectives, measures, performance targets and any explanatory narrative. Wal-Mart's packaging scorecard was introduced in the USA in 2006 as a measurement tool that allows suppliers to evaluate themselves relative to other suppliers, based on specifi c metrics..$^{15}$ In the packaging scorecard system, the suppliers are required to enter information regarding the packaging of each product supplied to WalMart. Each product packaging is then judged in terms of different metrics of sustainability that include GHG emissions produced per ton of packaging, size of packaging, use of raw materials, use of renewable energy, recycled content, transportation impacts and innovation. ${ }^{15}$

The SavvyPack ${ }^{\circledR}$ software allows users to create a similar scorecard where the inbuilt matrices are populated during data input for the LCI analysis. The scorecard results for the three packaging systems studied were created with the following matrices and the weighed average for each based closely to that utilized by Wal-Mart:

- $\quad 15 \%$ based on purchased material GHG.

- $\quad 15 \%$ based on sustainable material.

- $\quad 15 \%$ based on package to product ratio.

- $15 \%$ based on cube utilization. 
- $10 \%$ based on transportation distance.

- $10 \%$ based on recycled content.

- $10 \%$ based on recovery.

- $5 \%$ based on renewable energy.

- $5 \%$ based on energy innovation.

This scorecard provides valuable input to any supplier who may have to meet mandates by retailers, and can allow them to compare different packaging options for any product category.

\section{Allocation}

According to ISO 14040, allocation is defined as partitioning the input or output flows of a unit process to the product system under study. ${ }^{7}$ During the performance of LCA, allocation may be necessary when a process yields more than one product, i.e. a multifunctional process. ${ }^{16}$ This study focuses primarily on the liquid-milk-related package manufacturing, product filling and distribution components as related to the three primary $3.79 \mathrm{l}$ (1 gallon) HDPE containers, as well as the distribution packaging involved. Milk production was excluded in this study. Allocation was not used in this study since there was no more than one input or output in each unit process.

\section{System boundaries}

The system boundaries are illustrated in Figure 2. Milk production and processing were not included in this study. It was assumed that loss of product was the same for all three packaging systems studied. GHG in $\mathrm{CO} 2$ equivalents and energies were analysed based on materials (used to manufacture the packaging components, packaging of the product and the secondary packaging), processes (production facility and manufacturing processes for packaging components and packaging of the product) and transportation (raw materials, raw material packaging, finished product packaging from their point of origin to the production facility and transporting the finished product packaging from the production facility to the customer). 
The consulting milk producer and distributor has an in-house primary package manufacturing (extrusion blow moulding), product filling, unitizing and distribution system in place. The LCI data related to the outsourced packaging components, such as bottle closures, pressure sensitive labels, strapping, pallets and reusable crates, were collected from the vendors and were accounted for in this study. The unitized loads were assembled and loaded onto company-owned refrigerated trucks and delivered to their institutional and retail customers within a $402 \mathrm{~km}$ distance.

Primary packaging. The primary package designs studied are shown in Figure 1 and contain three common components: bottle (HDPE), closure (LDPE) and pressuresensitive labels. All of these designs are presently being used to distribute liquid milk to institutional and retail customers. The original and cube designs are more prevalent in the USA than the stackable design, which is currently being used by club stores such as Costco and Sam's Club. The different overall weights of the primary packages are provided in Table 1.

Secondary (distribution) packaging. As shown in the system boundary (Figure 2), the secondary packaging for the original and cube designs is similar and uses reusable packaging (RPCs and wooden pallets) as well as one-time use (plastic band straps) packaging components. Due to their ruggedized body and flat-top design, the wooden pallet is the only reusable packaging component used for the stackable design, which also uses one-time use corrugated fibreboard slip sheets and stretch wrap.

Table 1 shows details of the palletizing configurations for all three primary package designs studied. The palletizing configurations were based on the existing or recommended methodologies in consultation with the collaborating company.

In order to stabilize the load for the stackable design, corrugated fibreboard slip sheets were inserted between the pallet and the first tier, as well as between each tier with an area representing the pallet foot-print. The entire pallet was then stretch wrapped. This stretch wrap material may be recycled and was accounted for in the study at a recycling rate of $60 \%$.

The crates used as secondary packaging for the original and cube designs were recovered at a rate of $90 \%$ when a new shipment was dropped off and their weight, added to the returning truck shipments, was accounted for in the study. Based on the input from the milk producer/distributor, at an average use of one round trip per week for 10 years, the reusable crates experience 520 trips in an average service life. Energy and water consumption for sanitizing the crates for the closed-loop recovery system was integrated into the system boundary. Wooden pallets were assumed to have a useful life of 30 trips. $^{17}$ 


\section{DATA AND DATA QUALITY REQUIREMENTS}

\section{Production of raw materials}

The LCI data for production of all raw materials, namely HDPE (bottles), LDPE (labels, caps and stretch wrap), PET (band straps), PP (reusable crates), wood (pallets) and corrugated fi breboard (slip sheets), were obtained from the SavvyPack ${ }^{\circledR}$ software. Details of the databases sourced by this software are provided in the Methods section.

Based on the average US rate for municipal solid waste (MSW) stream treatment, the following post-consumer recycled content values were adopted for the raw materials used in all three packaging systems: corrugated fibreboard - 76.60\%, PP (reusable crates) - 4.70\%, PET (band straps) - 27.20\%, HDPE (milk bottles) - 29.30\%, LDPE (stretch wrap and bottle closures) $-14.00 \%$ and wood (pallets) $-14.80 \% .^{18}$

\section{Production of packaging components}

Data for production of the primary bottles (extrusion blow moulded on site), as well as the capping and labelling operations associated with them, were collected from the California-based milk producer/retailer. Information gathered from this source included plant layout, process equipment (eight head extrusion blow moulder, filler, etc.), support equipment (air compressors, chiller, resin handling equipment, reusable crate sanitizer, etc.), raw material transportation and product distribution networks.

The cradle-to-gate energy consumed or credited and $\mathrm{CO} 2$ equivalents generated to produce all packaging system components as well as those associated with the disposal were available from the LCI software database.

\section{Consumption stage}

The filling process composed of filling of all three types of primary containers with liquid milk, unitization, and storage prior to and during distribution of filled containers to institutional customers (on-site users) and retailers within $402 \mathrm{~km}$ from the processing and packing plant were assumed to result in similar impacts. The details of the packaging configurations for all three plastic containers are provided in Table 1 . The pallet dimensions were assumed to be $102 \times 122 \times 15 \mathrm{~cm}^{3}$ and the truck dimensions were $2.4 \times$ $16.2 \times 2.8 \mathrm{~m}^{3}$, with a weight capacity of $19800 \mathrm{~kg}$. The number of uses of pallets for all 
primary packages and the reusable crates for the original and cube containers are described in the Secondary (Distribution) Packaging section.

\section{Distances and transportation}

Distance from the resin (HDPE) supplier to the manufacturing, filling and distribution centre was approximated at $4828 \mathrm{~km}$ and included truck and train as the modes of transport. The remaining components of packaging systems associated with all three types of primary containers studied were assumed to be outsourced by the milk producer/retailer. Based on their input, the shipping distances for these components from the vendors to the product filling, unitizing and distribution facility were assumed as follows: milk crates (PP), wooden pallets, corrugated fibreboard slip sheets and band straps (PET) were shipped from $402 \mathrm{~km}$; label stock was shipped from $520 \mathrm{~km}$; and the stretch wrap and bottle closures (LDPE) were shipped from $1609 \mathrm{~km}$. The overall cradleto-gate energy and GHG ratios that converted energy use and GHG emissions to cradle equivalents for the truck and railcar transportation were available through the SavvyPack ${ }^{\circledR}$ LCI software.

\section{End-of-life}

The following hypothetical end-of-life scenarios in terms of landfill, incineration and recycling for all packaging components used in the three systems studied were considered:

- $\quad$ Scenario I - (40R/30I/30L) - 40\% recycling/30\% incineration/30\% landfi ll.

- $\quad$ Scenario II - (50I/50L) - 50\% incineration/50\% landfi ll.

Both scenarios assumed that no packaging was being retained by the institutional and retail customers and that all packaging materials underwent the waste treatment process. Scenario I is closest to the MSW treatment rates in the USA when observed across all materials used in the three systems studied. ${ }^{18}$ Growing climate and energy and environmental concerns, coupled with technological developments and regulatory changes, have triggered a renewed interest in MSW as an energy source with the potential to provide renewable energy while reducing GHG emissions and the need for landfi ll space. ${ }^{19}$

MSW-to-energy technologies being employed today include landfill gas capture (biogas made of approximately 50\% CO2 and 50\% methane), ${ }^{20}$ combustion (burning waste 
at approximately $980^{\circ} \mathrm{C}$ ), ${ }^{21}$ pyrolysis (MSW heated in the absence of oxygen at approximately $290-700^{\circ} \mathrm{C}$ ), ${ }^{22}$ gasifi cation (MSW heated with a small amount of oxygen at $\left.390-1650^{\circ} \mathrm{C}\right)^{23}$ and plasma arc gasifi cation (superheated plasma technology used to gasify MSW at approximately $5540^{\circ} \mathrm{C}$ ). ${ }^{24}$ Landfill gas capture has achieved the widest acceptance among these technologies with bio-energy programmes in place at 485 landfi lls in the USA in December 2008. ${ }^{19}$ Waste combustion has not grown in acceptance since 1996, and presently there are 88 waste-to-energy plants in operation in 25 states. ${ }^{25}$ Gasification and plasma arc technologies are still facing challenges towards commercial-scale use. ${ }^{26}$ Considering the increasing impact of landfill and incineration technologies, scenario II was used in this study.

\section{RESULTS}

As mentioned earlier, the main purpose of this study is to provide a relatively simple methodology to serve as a decision-making tool when more than one packaging solution could be available to a user. For this reason, we provide environmental emissions of the packaging systems studied (LCI) and not the burdens (LCA). A full LCA needs to be undertaken to understand the impacts of the environmental burdens. Also, because of recent mandates from retailers that use scorecards to judge packaged products in terms of different metrics of sustainability, this study incorporated it as a technique for comparing the three packaging systems studied.

\section{Discussion of LCI results}

Based on the data collected, GHG output (kg CO2 eq) and energy use/credit (MJ) per FU, and the scorecard results from the analysis were tabulated. Table 2 and Figures 3 and 4 show the impact of materials, processes and transportation on GHG output and energy uses for the two end-of-life scenarios considered. Table 3 shows the results in a scorecard format.

GHG

As presented in Table 2 and Figures 3 and 4, the stackable container-based packaging system contributed approximately $29 \%$ and $22 \%$ higher GHG emissions per FU as compared with the original and cube container-based packaging systems, respectively, for both end-of-life scenarios. When comparing the GHG emissions associated with the 
processes, including packaging manufacture, fi lling, distribution and disposal, the stackable packaging system was approximately $31 \%$ and $23 \%$ higher than the original and cube design-based systems. These results can be attributed primarily to more resin used per container for the stackable container for enabling distribution without any crates. This disadvantage was overcome by the stackable container in the GHG contributions as related to transportation for scenario II (50\% incineration and 50\% landfill), where the original system's contribution was $24 \%$ and that of the cube system was $27 \%$ higher than that of the stackable system. Scenario I ( $40 \%$ recycled, 30\% incineration and $30 \%$ landfill) caused the stackable design to produce $6 \%$ and $3 \%$ higher emissions in comparison with the original and cube systems.

\section{Energy}

As with the GHG portion of the analysis, the energy results were also studied for the two end-of-life scenarios. The stackable container-based packaging system consumed more overall energy than the other two systems. Its energy consumption was approximately $29 \%$ and $22 \%$ higher per FU as compared with the original and cube container-based packaging systems, respectively, for both end-of-life scenarios. When comparing the energy consumption associated with the processes involved, the stack-able packaging system's results were in line with those observed for the GHG emissions. These results can also be attributed to the additional resin used per stackable container. As related to scenario II, the transportation-related energy consumption of the stackable system was $23 \%$ and $26 \%$ lower than that for the original and cube designs, respectively. The same was $6 \%$ and $4 \%$ higher for the stackable design by comparison for scenario I.

Although the stackable container design is more cube-efficient and avoids the use of reusable crates, it uses approximately $30 \%$ and $23 \%$ more resin to achieve this as compared with the original and cube designs, respectively. As indicated by a past study, reusable plastic containers due to their multiple-use closed-loop deployment, though an expensive investment and contributing to considerable initial environmental burdens, can prove better than single-use packaging in terms of energy, GHG and solid waste. ${ }^{17}$ The primary benefit of the stackable container, i.e. cube efficiency, plays a relatively insignificant role when compared with the original and cube containers in a closed-loop setting such as that used by the milk producer and distributor consulted on this project. Also a key factor to note is that though the cube and stackable designs allow for more liquid milk to be shipped in refrigerated trailers between the packagers and consumers, the weight capacities of the trailers limit the benefits of improved cube efficiency utilization to be realized. 


\section{Scorecard results}

Table 3 shows the results in the SavvyPack ${ }^{\circledR}$ scorecard format. Although, as related to the LCI impacts, the original and cube design-based packaging systems performed better overall when compared with the stackable design, the scorecard ranked the stackable packaging system slightly higher than the alternatives. As may be seen, the stackable container-based packaging system equalled or scored lower in all categories, except in cube utilization, giving it a slightly higher overall rank than the other two packaging systems.

\section{CONCLUSIONS}

The main purpose of this study is to provide a relatively uncomplicated methodology to serve as a decision-making tool when more than one packaging solution is available to a user. It conducted an LCI analysis, and as related to a complete LCA study, the outcomes are limited. A full LCA needs to be undertaken to understand the impacts of the environmental burdens. Through the investigation of the three packaging systems in this study, it was shown that any changes to a primary package cause the distribution-related packaging and shipping configurations to alter, thereby causing changes to the overall LCI results. It was also shown that using LCI and scorecards as tools for 'sustainable' package design can be accomplished and can assist in uncovering overlooked aspects of a packaging system.

It was concluded that the use of RPCs for controlled environment distribution, such as that used by the collaborating company for this study, reduces the material requirements of the primary containers and therefore reduces the overall environmental impacts. Manufacturing of the primary containers made the largest contribution to the resource and energy consumptions. It was also found that although the transportationrelated impacts varied between the packaging systems for the two end-of-life scenarios considered, it had the lowest overall effect on the environmental impacts.

This study found that as related to both the GHG emissions and energy usage, production, manufacturing and product packaging-related processes had the highest overall environmental impact followed by materials used for the packaging systems and then by transportation of raw materials, finished product packaging from their point of origin to the production facility and transporting the finished product packaging from the

production facility to the customer. The study recommends that transportation weight 
limits must be considered as a limiting factor in package design for liquid products, as

trailers 'weigh out' before they 'cube out'. This means that on long refrigerated trailers, the product cannot be stacked as high as the available open space in the trailer.

As related to the LCI impacts, this study found that the original and cube containerbased packaging systems had a better overall per FU performance in comparison with the stackable design. However, the scorecard ranked the stackable packaging system slightly higher than the alternatives. Scorecards based on the Wal-Mart format do not accurately define the environmental impacts posed by packaging systems. Wal-Mart format seems to be biased towards both sizing of trailer fleets and the use of maximum space at retail stores.

\section{ACKNOWLEDGEMENTS}

The authors would like to acknowledge the support and funding provided by the Consortium for Packaging Technology and Science at California Polytechnic State University as well as the Allied Development Corporation in making this research possible.

\section{REFERENCES}

1. ISO. Environmental management - life cycle assessment - principles and framework. ISO 14040, 2006.

2. US Environmental Protection Agency. Life-cycle Assessment: Inventory Guidelines and Principles, EPA/600/R-92t245, Lewis Publishers: Boca Raton, FL, 1993.

3. A technical framework for life-cycle assessments. In Society of Environmental Toxicology and Chemistry, Fava JA, Denison R, Jones B et al. (eds). Society of Environmental Toxicology and Chemistry (SETAC) and SETAC Foundation for Environmental Eduction: Pensacola, FL, 1991 (August 18-23, 1990, Smugglers Notch, VT).

4. Consoli F, Allen D, Boustead I, Fava J, Franklin W, Jensen A, Oude N, Parrish R, Perriman R, Postlethwaite D, Quay B, Seguin J, Vigon B. Guidelines for Life-Cycle Assessment: A 'Code of Practice'. Environmental Science and Pollution Research 1994; 1(1): 55.

5. Guinée JB, Gorrée M, Heijungs R et al. Life Cycle Assessment: An Operational Guide to the ISO Standards. Kluwer Academic: Dordrecht, 2002.

6. Rebitzer G, Ekvall T, Frischknecth R et al. Life cycle assessment: goal and scope definition, inventory analysis, and applications. Environment International 2004; 30: 701-720.

7. Pennington DW, Potting J, Finnveden G et al. LCA, part 2: current impact assessment practice. Environment International 2004; 30: 721-739. 
8. Agricultural Statistics Board, USDA. Milk Production Report. 19 February 2010.

9. Innovation Center for US Dairy. US dairy sustainability initiative: a roadmap to reduce greenhouse gas emissions and increase business value, 2008;

http://www.dairycheckoff.com/NR/rdonlyres/4D6FA073-205C-4F09-

8BBB6B014E225B8E/0/DairyDeliverySystemsLCAProjectSummary063009.pdf [accessed 26

August 2009].

10. Keoleian G, Spitzley, DV. Guidance for improving life-cycle design and management of milk packaging. Journal of Industrial Ecology 1999; 3(1): 111-126.

11. Sonesson U, Berlin J. Environmental impact of future milk supply chains in Sweden: a scenario study. Journal of Cleaner Production 2003; 11: 253-266.

12. Berlin J, Sonesson U, Tillman A. Product chain actors' potential for greening the product life cycle: the case of the Swedish postfarm milk chain. Journal of Industrial Ecology 2008; 12(1): 95-11.

13. Mourad AL, Garcia EEC, Vilela GB, von Zuben F. Environmental effects from a recycling rate increase of cardboard of aseptic packaging system for milk using life cycle approach. International Journal of Life Cycle Assessment 2008; 13(2): 140-146.

14. Williams H, Wikstrom F, Lofgren M. A life cycle perspective on environmental effects of customer focused packaging development. Journal of Cleaner Production 2008; 16(7): 853-859.

15. Wal-Mart Press Release. 1 November 2006. Wal-Mart unveils 'packaging scorecard' to suppliers; http://walmartstores. com/pressroom/news/6039.aspx [accessed 20 February 2010].

16. Eide MH. Life cycle assessment (LCA) of industrial milk production. International Journal of Life Cycle Assessment 2002; 7(2): 115-126.

17. Singh S, Chonhenchob V, Singh J. Life cycle inventory and analysis of re-usable plastic containers and display-ready corrugated containers used for packaging fresh fruits and vegetables. Packaging Technology and Science 2006; 19(5): 279-293.

18. US Environmental Protection Agency. Municipal solid waste generation, recycling, and disposal in the United States: facts and figures 2008. 2009.

19. Environmental and Energy Study Institute. Reconsidering municipal solid waste as a renewable energy feedstock. Issue Brief July 2009.

20. Environmental Protection Agency. LFG energy project development handbook, Chapter 1. Environmental Protection Agency. 2009; http://www.epa.gov/lmop/res/pdf/pdh_chapter1.pdf, 2009 [accessed 18 May 2010].

21. Hazardous Waste Resource Center. Hazardous waste incineration: advanced technology to protect the environment. Environmental Technology Center. 2000; http://www.etc.org/technologicalandenvironmentalissues/treatmenttechnologies/ incineration/ [accessed 18 May 2010]. 
22. Sipilä K. municipal and commercial solid waste for pyrolysis (oils) and gasifi cation markets. VTT processes. 2002; http:// www.pyne.co.uk/docs/488.pdf [accessed 18 May 18].

23. Zafar S. Gasification of municipal solid waste. Earthtoys Magazine. 2009; http://www.earthtoys.com/emagazine.php?issue_number=09.06.01\&article=zafar [accessed 18 May 2010].

24. Westinghouse Plasma Corporation. What is plasma \& gasification? 2007; http://www.westinghouse-plasma.com/technology_solutions/what_is_plasma_gasification.php [accessed 18 May 2010].

25. Psomopoulos CS, Bourka A, Themelis, NJ. Waste to energy: a review of the status and benefits in the United States. Waste management. 2009; http://www.nmwda.org/news/documents/Tab3Psomopoulosetal2009WTEstatusandbenefi ts2. pdf [accessed 18 May 2010].

26. Ramsey/Washington County Resource Recovery Project. Updated research study: gasification, plasma, ethanol, and anaerobic digestion waste processing technologies. Foth Infrastructure and Environment, LLC. Project I.D.: 07R001, May 2008. 


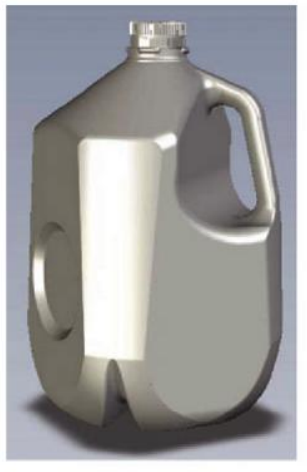

Original

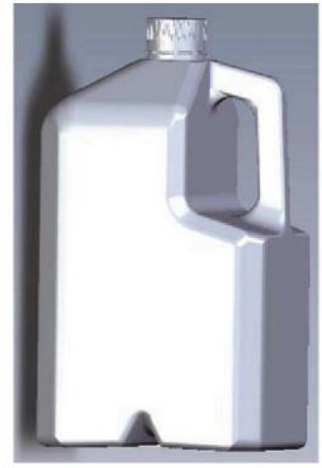

Cube

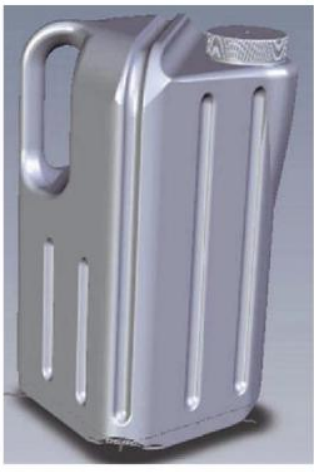

\section{Stackable}

Figure 1. Primary containers studied.

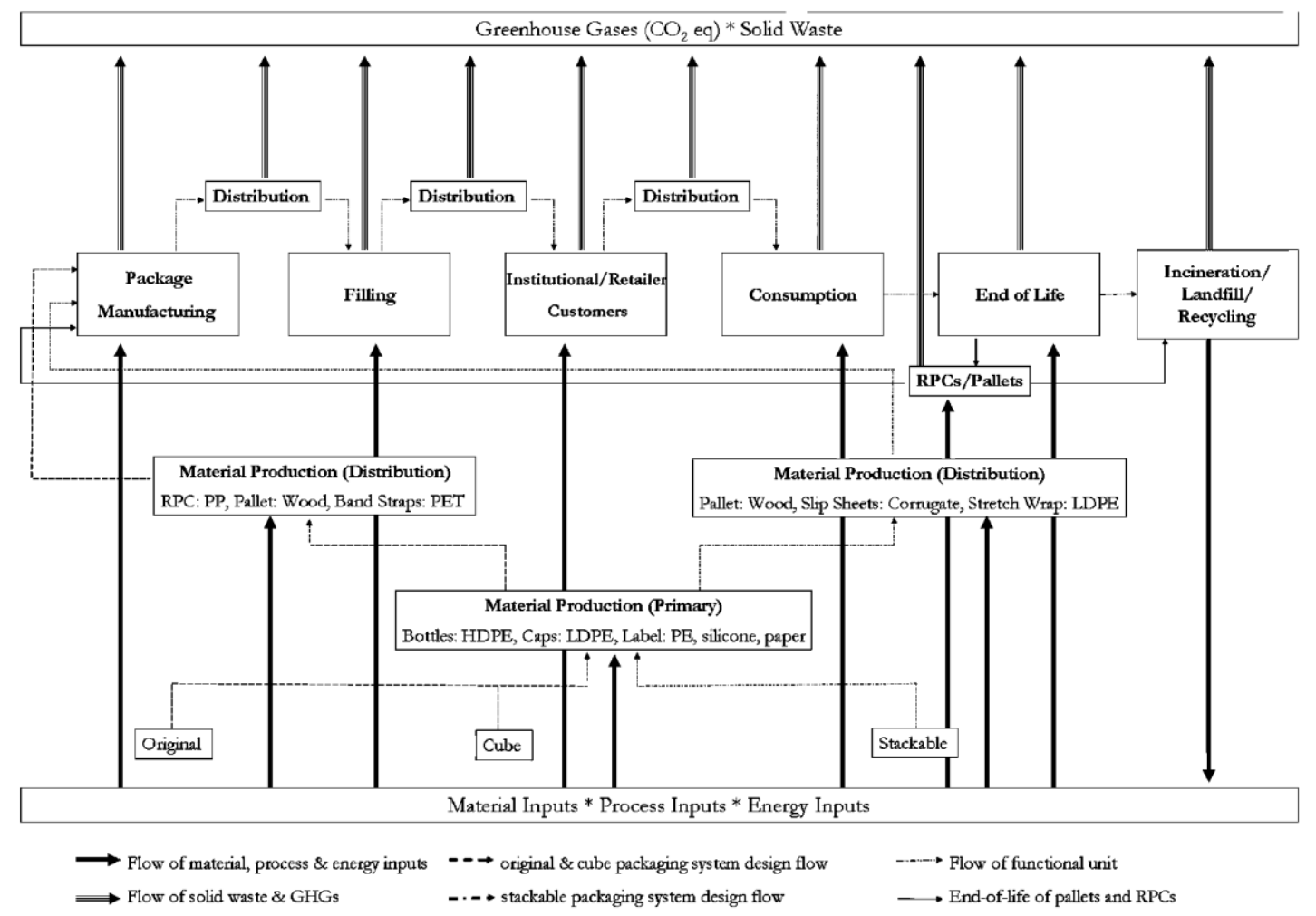

Figure 2. System boundaries of evaluated system. 
Table 1. Design differences for the 3.791 (1 gallon) packaging systems.

\begin{tabular}{|c|c|c|c|}
\hline & Original & Cube & Stackable \\
\hline $\begin{array}{l}\text { Weight of HDPE container } \\
\text { LDPE lid and adhesive } \\
\text { label (kg) }\end{array}$ & 0.065 & 0.072 & 0.093 \\
\hline Weight of crate $(\mathrm{kg})$ & 3.18 & 2.27 & 0 \\
\hline Secondary packaging & $\begin{array}{l}\text { Crates hold } 6 \\
\text { containers, are } \\
\text { stacked } 6 \text { high, } 7 \\
\text { stacks per pallet and } \\
\text { banded around top } \\
\text { and bottom tier }\end{array}$ & $\begin{array}{l}\text { Crates hold } 4 \\
\text { containers, are } \\
\text { stacked } 6 \text { high, } 12 \\
\text { stacks per pallet and } \\
\text { banded around top } \\
\text { and bottom tier }\end{array}$ & $\begin{array}{l}\text { Containers stacked } \\
63 \text { per tier, } 4 \\
\text { high, corrugate } \\
\text { slip sheets } \\
\text { between tiers and } \\
\text { stretch wrapped. }\end{array}$ \\
\hline Containers per pallet & 252 & 288 & 252 \\
\hline $\begin{array}{l}\text { Total weight of palletized } \\
\text { load }(\mathrm{kg})\end{array}$ & $1.14 \times 10^{3}$ & $1.32 \times 10^{3}$ & $1.02 \times 10^{3}$ \\
\hline $\begin{array}{l}\text { Total height of palletized load } \\
\text { (m) }\end{array}$ & 1.98 & 1.98 & 1.17 \\
\hline Product weight per pallet $(\mathrm{kg})$ & 988 & $1.13 \times 10^{3}$ & 995 \\
\hline $\begin{array}{l}\text { Packaging weight per pallet } \\
(\mathrm{kg})\end{array}$ & 155 & 185 & 23 \\
\hline Number of pallets per truck & 17 & 15 & 18 \\
\hline Product weight per truck $(\mathrm{kg})$ & $1.68 \times 10^{3}$ & $1.70 \times 10^{3}$ & $1.80 \times 10^{3}$ \\
\hline $\begin{array}{l}\text { Packaging weight per truck } \\
(\mathrm{kg})\end{array}$ & $2.63 \times 10^{3}$ & $2.77 \times 10^{3}$ & 418 \\
\hline Total weight per truck $(\mathrm{kg})$ & $1.94 \times 10^{3}$ & $1.97 \times 10^{3}$ & $1.83 \times 10^{3}$ \\
\hline
\end{tabular}

Table 2. GHG and energy consumption.

\begin{tabular}{lccccc}
\hline & \multicolumn{2}{c}{ Energy $(\mathrm{MJ} / \mathrm{FU})$} & & \multicolumn{2}{c}{$\mathrm{GHG}\left(\mathrm{kg} \mathrm{CO}_{2} \mathrm{eq} / \mathrm{FU}\right)$} \\
\cline { 2 - 3 } \cline { 6 - 7 } Container & $40 \mathrm{R} / 30 \mathrm{I} / 30 \mathrm{~L}$ & $50 \mathrm{I} / 50 \mathrm{~L}$ & & $40 \mathrm{R} / 30 \mathrm{I} / 30 \mathrm{~L}$ & $50 \mathrm{I} / 50 \mathrm{~L}$ \\
\hline Original & 22.3 & 22.3 & & 1.27 & 1.27 \\
Cube & 24.6 & 24.6 & & 1.40 & 1.40 \\
Stackable & 31.8 & 31.5 & & 1.81 & 1.78 \\
\hline
\end{tabular}

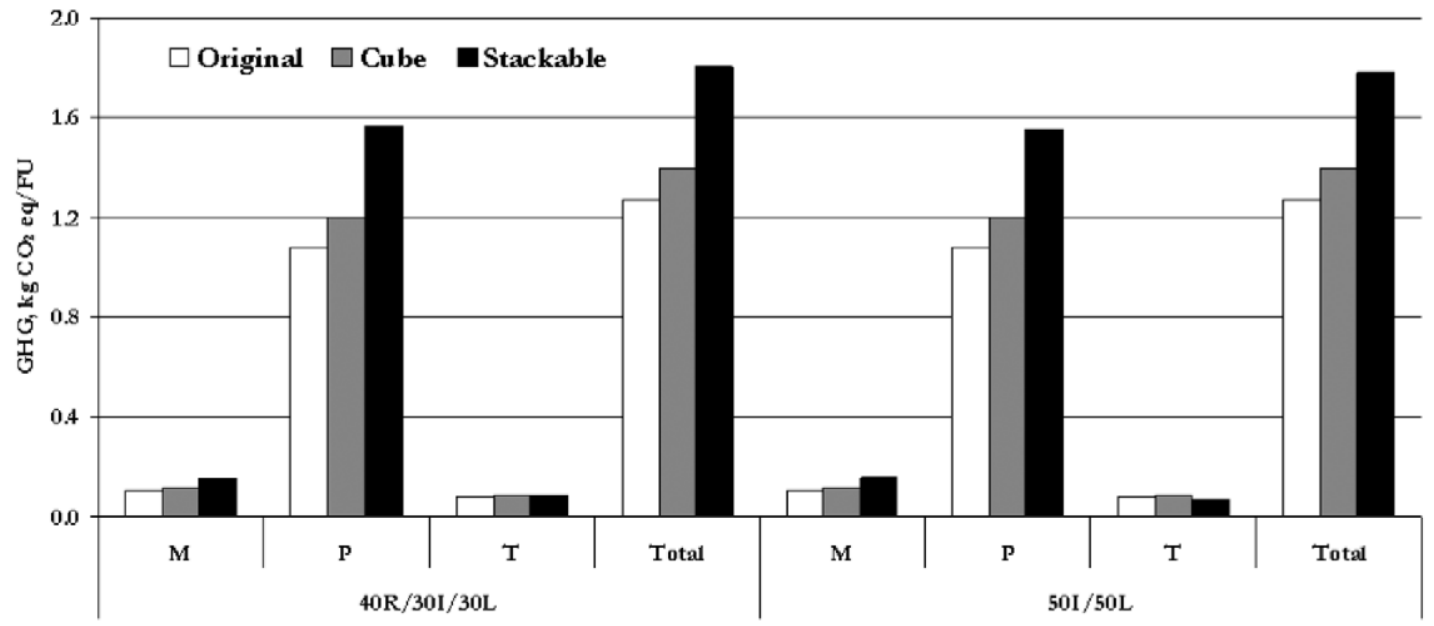

Figure 3. GHG results. M, materials; $\mathrm{P}$, processes; $\mathrm{T}$, transportation. 


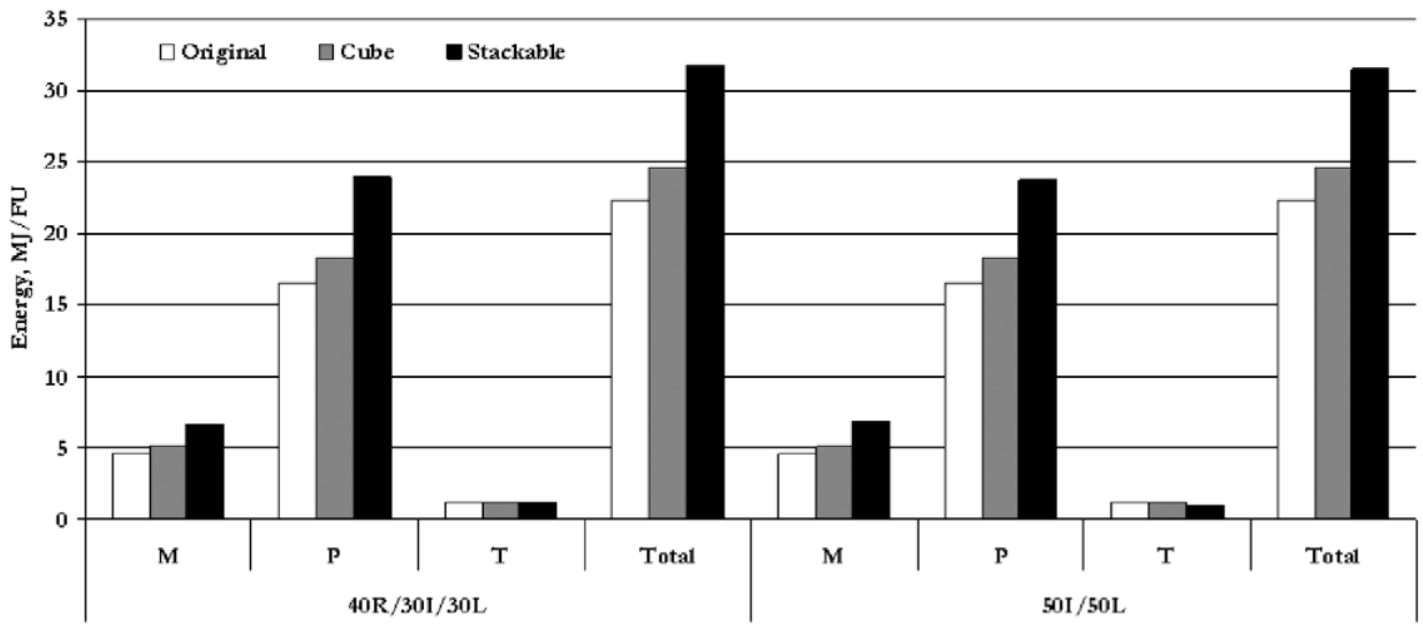

Figure 4. Energy usage results. M, materials; $\mathrm{P}$, processes; T, transportation.

Table 3. Packaging scorecard results.

\begin{tabular}{lcccc}
\hline Criterion & Max score & Original & Cube & Stackable \\
\hline Purchased material GHG & 15 & 14.7 & 14.7 & 14.4 \\
Sustainable material & 15 & 14.9 & 14.9 & 14.7 \\
Transportation distance & 10 & 10.0 & 10.0 & 10.0 \\
Package to product ratio & 15 & 14.7 & 14.6 & 14.2 \\
Cube utilization & 15 & 10.1 & 11.0 & 13.0 \\
Recycled content & 10 & 9.79 & 9.74 & 9.57 \\
Recovery & 10 & 9.42 & 9.35 & 9.09 \\
Renewable energy & 5 & 0.00 & 0.00 & 0.00 \\
Energy innovation & 5 & 0.00 & 0.00 & 0.00 \\
Total & 100 & 83.7 & 84.2 & 85.0 \\
\hline
\end{tabular}

